\title{
Psychosocial correlates of perceived stress among undergraduate medical students in Nigeria
}

\author{
Bawo Onesirosan James ${ }^{1}$, Ibironke Felicia Thomas ${ }^{2}$, Joyce Ohiole Omoaregba ${ }^{1}$, \\ Esther O. Okogbenin ${ }^{3}$, Kingsley Mayowa Okonoda $^{4}$, Abdu Wakawa Ibrahim ${ }^{5}$, Auwal S. Salihu ${ }^{6}$, \\ Yewande 0. Oshodi ${ }^{7}$, Andrew. O Orovwigho ${ }^{8}$, Paul C. Odinka ${ }^{9}$, George O. Eze ${ }^{10}$, \\ Godwin C. Onyebueke ${ }^{11}$, Benjamin Efi Aweh ${ }^{12}$
}

${ }^{1}$ Department of Clinical Services, Federal Neuropsychiatric Hospital, Benin City, Nigeria

${ }^{2}$ Synapse Services Centre for Psychological Medicine, Lagos, Nigeria

${ }^{3}$ Department of Psychiatry, College of Medicine, Ambrose Alli University, Ekpoma, Edo State, Nigeria

${ }^{4}$ Department of Psychiatry, University of Jos, Plateau State, Nigeria

${ }^{5}$ Department of Mental Health, College of Medical Sciences, University of Maiduguri, Borno State, Nigeria

${ }^{6}$ Department of Psychiatry, Bayero University, Kano, Nigeria

${ }^{7}$ Department of Psychiatry, College of Medicine, University of Lagos, Lagos State, Nigeria

${ }^{8}$ Department of Clinical Services, Federal Neuropsychiatric Hospital, Enugu, Enugu State, Nigeria

${ }^{9}$ Department of Psychological Medicine, College of Medicine, University of Nigeria, Nsukka, Enugu State, Nigeria

${ }^{10}$ University of Sierra Leone Teaching Hospital, Freetown, Sierra Leone

${ }^{11}$ Enugu State University of Science and Technology, Parklane, Nigeria

${ }^{12}$ Irrua Specialist Teaching Hospital, Edo State, Nigeria

Correspondence: Bawo O. James, Department of Clinical Services, Federal Neuro-Psychiatric Hospital, P.M.B 1108, Benin-City, Edo Sate, Nigeria. E-mail: bawojames@yahoo.com

Accepted: September 23, 2017

\begin{abstract}
Objectives: To assess the prevalence and factors associated with perceived stress among medical students.

Methods: A cross-sectional study of students ( $n=623$ ) selected across eight medical schools in Nigeria. A structured questionnaire obtained socio-demographic characteristics, alcohol use (Alcohol Use Disorders Identification Test), other psychoactive drug use (Drug Abuse Screening Test), anxiety/depression symptoms (Hospital Anxiety Depression Scale) and stress (Perceived Medical School Stress Scale). We performed bivariate analysis using the chisquared test, t-test and one-way ANOVA, with multiple regression analysis for multivariate testing in analysing the data.

Results: Most students reported experiencing medical school stress. Female participants were more likely to perceive medical school as competitive $\left(t_{(621)}=1.17\right.$,

$\mathrm{p}=0.001)$. Nearly a quarter; $21.3 \%(\mathrm{n}=133)$ and $28.6 \%$ $(\mathrm{n}=178)$ reported depression and anxiety symptoms respectively. Approximately 4.2\% $(\mathrm{n}=26)$ were dependent on alcohol, while $14.1 \%(n=88)$ had 'low-risk use' for other psychoactive substances. In the multiple regression model, lack of finance $(B=2.881, p=0.001)$, weak adherence to religious faith $(\mathrm{B}=2.376, \mathrm{p}=0.001)$, anxiety symptoms $(B=-2.231, p=0.002)$, problematic alcohol use $(B=5.196$, $\mathrm{p}=0.001)$ and choice of study influenced by parents $(B=-$ $3.105, p=0.001$ ) were predictors of greater perceived stress.

Conclusions: Medical students in Nigeria report high levels of stress. Incorporating stress reduction strategies in the medical curriculum, and the input of students in providing feedback regarding the methods and styles of undergraduate medical education is required.
\end{abstract} $\mathrm{p}=0.003)$, less likely to see medical school as a threat ( ${ }_{(621)}$ $=-2.70, \mathrm{p}=0.01)$ or worry about finances $\left(\mathrm{t}_{(621)}=-4.80\right.$,

Keywords: Medical students, stress, Nigeria, psychosocial correlates

\section{Introduction}


Research on stress or perceived stress among undergraduate students in general and medical students is growing. ${ }^{1-6}$ The available body of evidence suggests that certain factors either singly or in combination contribute to the development or perpetuation of stress in undergraduate programs. ${ }^{5,7}$ Factors include those unique to the individual, that either protect, predispose, or perpetuate stress, or factors considered 'environmental'. 'Personal' factors include personality predisposition, coping style, psychological and physical health, psychoactive substance use and religious adherence. ' 'Environmental' factors, on the other hand, may comprise the curriculum, living and study conditions, as well as financing. ${ }^{9,10}$

Medical students consistently report higher levels of stress or perceived stress when compared to other students or the general population., ${ }^{411}$ Differences in cultural and geographical setting, study design, year of study of the medical student sample, and assessment tools may explain variation in the prevalence rates.

Modifications of the transactional model of stress underlie study designs in earlier reports. ${ }^{5}$ Vitaliano classed students into 'resistors', whose stress levels did not increase over their training period, 'persistors' whose scores were high at baseline and remained so over their course of study. The third; 'adaptors' whose high scores at baseline reduced over the course of study and 'maladaptors' whose low scores at baseline worsened over the course of study. ${ }^{7}$ They also identified personality, anger expression and coping as distinguishing factors among the groups. ${ }^{5,8,12,13} \mathrm{~A}$ recent report confirms via robust structural equation models, that personal resources by way of resilience, self-efficacy, and optimism impact on perceived stress. These affect how individuals cope with the demands of study, tension from interpersonal interactions and worries from expectations and consequences of studying. ${ }^{5}$ Perceived stress also mediates how emotional distress links with symptoms of anxiety and depression. ${ }^{6,14,15}$

A sizable body of evidence exists in the literature on perceived stress and its psychosocial correlates. However most studies conducted in Europe, the Middle East, and North America cannot be generalised to sub-Saharan Africa. In Nigeria, the period of undergraduate medical education has been reported as a particularly stressful, ${ }^{16}$ with students reporting high levels of stress. ${ }^{17}$ This study aimed to ascertain the magnitude of perceived stress among medical students and compare findings with reference samples from other countries. In addition, it aimed to explore the pattern of perceived stress and identify if any, gender differences in perceived stress. Certain factors (financial status, motivation to study the course, religious adherence, psychoactive substance use and emotional health) identified from published literature to either improve or worsen stress were tested to determine the association with perceived stress in this cohort.

\section{Methods}

\section{Study design and sample size}

This was a cross-sectional descriptive study of undergraduate medical students in their clinical years at accredited medical schools (public and privately owned) in Nigeria. Medical education in Nigeria comprises three years of preclinical studies followed by three years of clinical coursework, after 12 years of basic primary and secondary education. There are 31 medical schools in the country. Twentyseven are fully accredited and four partially accredited. ${ }^{18}$

Thirty-one medical schools are spread across six geopolitical zones. We selected eight accredited medical schools using probability sampling: University of Lagos (SouthWest), the University of Nigeria and Enugu State University (South-East), Bayero University (North-West), University of Maiduguri (North-East), University of Jos (North Central) and Ambrose Alli University and Igbinedion University (South-South). We recruited 635 students from the eight selected medical schools.

At each university, the Ethics Committee (IUO \& AAU: Ethics Committee FNPH, Benin-City; BUK: Bayero University Ethics Review Committee; UNILAG: University of Lagos Ethics Review Committee; UNIMAID: University of Maiduguri Ethics Review Board; UNIJOS: Jos University Ethics Review Committee; ESUT \& UNN: Enugu State University Ethics Committee) reviewed and approved the study protocol. We assured each participant of the confidentiality of their responses. We collected no identifying information to ensure anonymity. We assured students that no adverse consequence would result from their decision not to participate in the study as participation was voluntary. They were also informed that findings would be used for research purposes only and disseminated in a scientific conference or a peer review journal.

At each selected medical school, we invited medical students in their clinical years (400-600 levels) to participate in the study. We randomly selected a class from the 400 to 600 levels. In a selected class, all students were invited after at a randomly selected lecture, to participate. At each site, the researcher ensured that the lecture selected was not the one he/she was delivering to prevent bias. The site researcher explained the nature and purpose of the study and obtained written consent. We distributed the self-administered questionnaire and retrieved completed ones 30 minutes after. We made efforts to ensure adequate spacing during class due to the sensitive nature of some questions to allow unbiased responses. We excluded students who did not attend the randomly selected lecture. Ninety-four students from all the sites did not participate in the randomly selected lecture. These students were similar in age and gender when compared with participants. The study took place between November 2014 and August 2015. 


\section{Instruments}

\section{Socio-demographic Questionnaire}

We designed this questionnaire to capture variables such as age, gender, marital status, religious adherence, as well as a source of funding for the medical school.

\section{Perceived Medical School Stress Scale}

Stress perception among students was measured using the adapted version, 15 of the Perceived Medical School Stress (PMSS) questionnaire. ${ }^{7,12}$ It comprises 13 items that present response options on a five-point Likert scale, ranging in the original version and the results of Holm et al. (2010) from "strongly disagree: 0 " to "strongly agree: 4". Total scores range between 0 and 52, with higher scores indicating greater perceived stress. In a recent study, the Cronbach's alpha coefficient for the PMSS was $0.81 .{ }^{19}$ In this study; the PMSS had good face validity and internal consistency with a Cronbach's alpha of 0.74 .

\section{Alcohol Use Disorder Identification Test}

The Alcohol Use Disorders Identification Test (AUDIT) is a simple ten-question test developed by the World Health Organisation to determine harmful alcohol use. Responses are scored between 0 and 4 , with total scores ranging between 0 and 40 . Higher scores indicate a greater risk of alcohol-related problems. The test was designed to be used internationally and was validated in a study using patients from six countries. ${ }^{20}$ Questions 1-3 deal with alcohol consumption, 4-6 relate to alcohol dependence and 7-10 consider alcohol-related problems. A validation study in Nigeria recommended a cut-off of 5 for hazardous alcohol use, with cut-offs of 7 and 9 for harmful use and alcohol dependence respectively. ${ }^{21}$ The AUDIT demonstrated good sensitivity; $100 \%$ and specificity; $92.1 \%$ in a recent study from Nigeria. ${ }^{22}$

\section{Drug Abuse Screening Test}

The Drug Abuse Screening Test (DAST) is a 10-item selfadministered tool that provides a quick assessment of drug use problems. Initial psychometric assessment involved a cohort of 256 clients with substance use problems. ${ }^{23}$ The DAST10 is as reliable as the longer DAST-20. The DAST-10 has been validated in the varied setting; substance-abuse patients, ${ }^{24}$ primary care,${ }^{25}$ in the workplace, ${ }^{26}$ and adapted for use with adolescents. ${ }^{27}$ Suggested scoring for the DAST10: "0 No problem”, "1-2 Low level”, "3-5 Moderate level”, “6-8 Substantial level”, "9-10 Severe level”. ${ }^{23}$

\section{Hospital Anxiety and Depression Scale}

Hospital Anxiety and Depression Scale (HADS), ${ }^{28}$ screens for anxiety and depression symptoms. The HADS is a 14item scale; seven items each relate to anxiety and depression. Each item response derives a score from 0-3, with total scores for each subscale ranging between 0 and 21. Caseness on the HADS has been determined with at least a score of 8 out of 21. Abiodun also obtained an optimum cut-off point of 8 for the HAD anxiety and depression sub-scales in a validity study conducted in Nigeria. ${ }^{29}$

\section{Data analysis}

We coded data into an electronic spreadsheet (SPSS version 20). We summarized the data using descriptive statistics and presented them in tables. We tested associations between the dependent variable (perceived stress total score) and categorical dependent variables using the Student's t-test/one-way ANOVA). For analysis, age was dichotomised into: ' $\geq 24$ years' and ' $<24$ years'; type of accommodation was dichotomised into: 'on-campus hostel' and 'others'. We regrouped adherence to faith into 'strong' (very strong, strong), 'fair' (fair), and 'poor' (very poor, poor). Similarly, AUDIT scores were dichotomised into two groups: 'No problem' and 'Problem drinking'. Scores on the DAST-10 were dichotomised into: 'No problem' and 'Problematic use'. The scores on the anxiety subscale and the depression subscale of the HADS respectively were dichotomised into: 'absent' and 'present'. Significant associations on bivariate testing between perceived stress and psychosocial correlates were entered into a multiple regression model to identify predictors of perceived medical school stress. We set the level of significance a priori at $\mathrm{p}<0.05$.

\section{Results}

\section{Socio-demographic characteristics of medical students}

We analysed questionnaires from 635 students. Thirteen incompletely filled questionnaires were and excluded from the analysis. Therefore we analysed a total of 623 questionnaires. Of the 623 medical students who participated in this study, $359(57.6 \%)$ were male. The mean age was 23.91 $( \pm 3.67)$ years. Most participants were single $(n=509,81.7 \%)$ and Christian ( $\mathrm{n}=459,73.7 \%)$. Most did not have a previous higher degree $(n=556,89.2 \%)$, and the majority reported that they obtained funding for their education from their parents or a close relative $(n=545,87.5 \%)$. Participants described the ease of funding as "easy but could be better" $(51.2 \%)$, while $5.6 \%$ found it "difficult" to fund their education. Over half $(n=356,57.1 \%)$ lived in hostels on the university campus. The 'desire to help others' was a common factor that had motivated most students (63.3\%) to choose to study medicine. See Tables 1 and 2.

\section{Clinical characteristics of medical students}

A majority did not report problematic drinking when assessed on the AUDIT $(n=570,91.5 \%)$ however, twenty-six students $(4.2 \%)$ were dependent on alcohol. Similarly, a majority reported no problems on the DAST-10 regarding use of other psychoactive substances, although $14.1 \%$ of them had 'low risk' problems with the use of psychoactive 
Table 1. Socio-demographic characteristics of participants

\begin{tabular}{lcc}
\hline Variable & Frequency & $\%$ \\
\hline Age class & & \\
<24 years & 310 & 49.8 \\
>24 years & 313 & 50.2 \\
Mean age (SD) & $23.91(3.67)$ & \\
Gender & & \\
Female & 264 & 42.4 \\
Male & 359 & 57.6 \\
Marital status & & \\
Single & 553 & 88.8 \\
Co-habiting & 9 & 1.4 \\
Married & 61 & 9.8 \\
Religion & & \\
Christianity & 459 & 73.7 \\
Islam & 161 & 25.8 \\
None & 3 & 0.5 \\
Adherence to faith & & \\
Very strong & 154 & 24.7 \\
Strong & 239 & 38.4 \\
Fair & 178 & 28.6 \\
Poor & 42 & 6.7 \\
Very poor & 10 & 1.6 \\
Previous higher degree & & 10.8 \\
Yes & 67 & 89.2 \\
No & 556 & \\
\hline
\end{tabular}

substances. One hundred and seventy-eight students (28.6\%) were screen positive for anxiety, while $21.3 \%$ were screen positive for depressive symptoms as rated by the HADS (see Table 3).

\section{Pattern of perceived medical students stress}

Table 4 shows the scores obtained on the 13 items of the PMSS. The mean scores \pm SD for an item were highest on items 7; 'medical school more competitive than I expected'

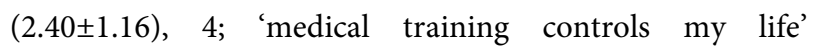
$(2.27 \pm 1.28)$, and 12 ; 'concern about personal finances' $(2.18 \pm 1.28)$. Female students were significantly more likely to report that medical school was competitive; $(2.56 \pm 1.14$ vs. $2.28 \pm 1.17, \mathrm{t}_{(621)}=2.95, \mathrm{p}=0.003$ ) and less likely to see medical school as more of a threat than a challenge $\left(1.30 \pm 1.15\right.$ vs. $\left.1.56 \pm 1.25, \mathrm{t}_{(621)}=-2.70, \mathrm{p}=0.01\right)$ and be less concerned about personal finances $(1.90 \pm 1.29$ vs. $2.39 \pm 1.24$, $\left.\mathrm{t}_{(621)}=-4.80, \mathrm{p}<0.001\right)$.

Table 2. Psychosocial characteristics of participants

\begin{tabular}{lcc}
\hline Variable & Frequency & $\%$ \\
\hline Source of funds & & \\
Self-funded & 44 & 7.1 \\
Parents/family & 545 & 87.5 \\
$\quad$ Scholarship & 34 & 5.4 \\
Ease of funding & 123 & \\
Very easy & 319 & 19.7 \\
Easy, but could be better & 146 & 51.2 \\
Difficult & 35 & 23.4 \\
Very difficult & 356 & 5.7 \\
Accommodation type & 205 & 57.1 \\
On-campus residence & 62 & 32.9 \\
Off-campus residence & & 10.0 \\
Family residence & 56 & \\
What influenced decision? & 94 & 15.1 \\
Parents' choice & 77 & 12.3 \\
Role model & 396 & 63.6 \\
Financial stability & & \\
Desire to help others &
\end{tabular}

Int J Med Educ. 2017;8:382-388

\section{Correlates of medical school-related stress}

Students who hold a previous higher degree reported significantly less stress compared to those who held none $\left(22.36 \pm 6.63\right.$ vs. $\left.24.37 \pm 7.99, \mathrm{t}_{(621)}=-1.98, \mathrm{p}=0.048\right)$. Those who found it 'easy' to fund their education also had significantly lower stress levels $\left(22.02 \pm 8.77\right.$ vs. $24.68 \pm 7.55, \mathrm{t}_{(621)}=-3.37$, $\mathrm{p}=0.001)$. Students who choose to study medicine out of a desire to help others had significantly less stress $\left(\mathrm{F}_{(3 / 621)}\right.$ $=10.40, \mathrm{p}<0.001)$. Participants who rated their adherence to their faith as poor were significantly more likely to report greater stress $\left(\mathrm{F}_{(2 / 621)}=39.44, \mathrm{p}<0.001\right)$.

Table 3. Pattern of psychoactive substance use and psychiatric morbidity

\begin{tabular}{lcc}
\hline Variable & Frequency & $\%$ \\
\hline Alcohol use (AUDIT) & & \\
No problem & 570 & 91.5 \\
Hazardous & 16 & 2.6 \\
Harmful use & 11 & 1.7 \\
Dependence & 26 & 4.2 \\
Other psychoactive substance use (DAST-10) & \\
No problem & 493 & 79.1 \\
Low risk & 88 & 14.1 \\
Moderate risk & 33 & 5.3 \\
Substantial risk & 4 & 0.6 \\
Severe risk & 5 & 0.8 \\
Anxiety (HADS-A) & & \\
Absent & 445 & 71.4 \\
Present & 178 & 28.6 \\
Depression (HADS-D) & & \\
Absent & 490 & 78.7 \\
Present & 133 & 21.3 \\
\hline
\end{tabular}

Students with 'problem drinking' reported significantly more stress $\left(29.74 \pm 8.37\right.$ vs. $23.63 \pm 7.63, \mathrm{t}_{(621)}=-5.53$, $\mathrm{p}<0.001)$. Presence of anxiety $(26.54 \pm 7.95$ vs. $23.20 \pm 7.65$, $\left.\mathrm{t}_{(621)}=-4.87, \quad \mathrm{p}<0.001\right)$ and depression $(26.28 \pm 8.29$ vs. $\left.23.58 \pm 7.67, \quad \mathrm{t}_{(621)}=-3.54, \quad \mathrm{p}<0.001\right) \quad$ was significantly associated with greater perceived stress (see Table 5).

\section{Predictors of medical school-related stress}

Significant socio-demographic and clinical correlates of medical school stress were entered into a multiple regression model using the forced entry method. Reported funding of medical school as difficult $(\mathrm{B}=2.881, \mathrm{p}<0.001)$, parents' choice as a motivation for a career in medicine $(\mathrm{B}=-3.105, \mathrm{p}<0.001)$, poor adherence to faith $(\mathrm{B}=2.376$, $\mathrm{p}<0.001)$, problem drinking $(\mathrm{B}=5.196, \mathrm{p}<0.001)$, and anxiety $(\mathrm{B}=2.231, \mathrm{p}<0.002)$ were predictors of perceived stress encountered in medical school (Table 6).

\section{Discussion}

In this study, we evaluated the relationship between perceived stress among medical students, their use of alcohol and other psychoactive substances, and psychiatric morbidity (anxiety symptoms and depressive symptoms). Overall medical students reported high rates of perceived stress, with a sizable proportion reporting alcohol use. Anxiety and depression symptoms were common. There was a significant association between greater perceived stress and poor funding, parental preference influencing the 
James et al. - Perceived stress in medical students

Table 4. Gender differences on the perceived stress in medical students

\begin{tabular}{|c|c|c|c|c|c|c|c|c|c|}
\hline \multirow{2}{*}{ PMSS } & \multicolumn{2}{|c|}{ Total } & \multicolumn{2}{|c|}{ Females $(n=264)$} & \multicolumn{2}{|c|}{ Males $(n=359)$} & \multirow{2}{*}{$t$} & \multirow{2}{*}{ p-value } & \multirow{2}{*}{$95 \% \mathrm{Cl}$} \\
\hline & Mean & SD & Mean & SD & Mean & SD & & & \\
\hline Feelings of anonymity and isolation & 1.90 & 1.16 & 1.88 & 1.17 & 1.91 & 1.16 & -0.31 & 0.76 & $-0.22-0.16$ \\
\hline Inability to endure long hours & 1.28 & 1.15 & 1.27 & 1.09 & 1.28 & 1.20 & -0.12 & 0.90 & $-0.20-0.17$ \\
\hline Unclear expectations of faculty & 1.14 & 1.01 & 1.09 & 0.91 & 1.18 & 1.08 & -1.03 & 0.30 & $-0.25-0.08$ \\
\hline Medical training controls whole life & 2.27 & 1.28 & 2.20 & 1.31 & 2.32 & 1.25 & -1.22 & 0.22 & $-0.33-0.08$ \\
\hline Unable to master entire knowledge & 1.80 & 1.26 & 1.81 & 1.19 & 1.79 & 1.31 & 0.19 & 0.85 & $-0.18-0.22$ \\
\hline Demanding physician role & 2.07 & 1.14 & 2.03 & 1.15 & 2.09 & 1.13 & -0.67 & 0.51 & $-0.24-0.12$ \\
\hline Competitive medical school & 2.40 & 1.16 & 2.56 & 1.14 & 2.28 & 1.17 & 2.95 & 0.003 & $0.09-0.46$ \\
\hline Education as baptism of fire & 2.02 & 1.19 & 1.95 & 1.19 & 2.08 & 1.19 & -1.25 & 0.21 & $-0.31-0.07$ \\
\hline Success despite administration & 2.01 & 1.05 & 1.98 & 1.06 & 2.04 & 1.05 & -0.76 & 0.45 & $-0.23-0.10$ \\
\hline Medical school cold, impersonal & 1.85 & 1.10 & 1.77 & 1.08 & 1.92 & 1.10 & -1.66 & 0.10 & $-0.32-0.03$ \\
\hline Medical school more threat than challenge & 1.45 & 1.21 & 1.30 & 1.15 & 1.56 & 1.25 & -2.70 & 0.01 & $-0.46--0.07$ \\
\hline Worries about personal finances & 2.18 & 1.28 & 1.90 & 1.29 & 2.39 & 1.24 & -4.80 & 0.001 & $-0.69--0.29$ \\
\hline Worries about accommodation & 1.79 & 1.34 & 1.67 & 1.33 & 1.88 & 1.34 & -1.87 & 0.06 & $-0.42-0.01$ \\
\hline Total & 24.15 & 7.87 & 23.46 & 7.44 & 24.66 & 8.15 & -1.89 & 0.06 & $-2.46-0.05$ \\
\hline
\end{tabular}

choice of study, self-rated poor adherence to religious faith and anxiety symptoms.

Overall, female students reported lower rates of perceived stress compared to their male counterparts, a finding inconsistent with a similar study from Pakistan. ${ }^{4}$ Shah and colleagues note that cultural restrictions placed on women in Pakistan limit involvement in a socio-cultural activity that may reduce stress. In contrast, though restrictions on what women may do in society exist in Nigeria, they are probably more specific to those in the lower social class. A sizable proportion of females who undergo a degree in medicine come from middle to upper-class families.

Male students were more concerned about personal finances, which contrasts with reports from Europe where female students were more likely to complain about finances. ${ }^{30,31}$ It has been theorised that females in Europe and North America worry more about finances because males would prefer to drop out of school to work, unlike females who fear that dropping out of school and working would earn them less starting pay compared to males. The exact reason for the discrepancy in this environment is unknown. We hypothesize however that, male medical students would probably be less likely to get funds from parents/relatives, or may spend more.

Students who rated their ease of obtaining funds for medical school as difficult were significantly more likely to report stress even after adjusting for other variables. Most students get funding for medical school from family/relatives. Student loans are non-existent in Nigeria, and the few who are on scholarships are under pressure to maintain satisfactory performance or risk losing their scholarship. In the face of dwindling subventions from the government to universities, higher institutions routinely increase fees to remain open. This way, they pass on the cost of running the school to the students. For private medical schools, the cost of tuition is quite prohibitive. This study provides evidence that students who are unable to fund their courses have higher associated perceived stress. Stress has been consistently reported to impact academic performance. $^{32}$

Table 5. Correlates of perceived stress

\begin{tabular}{|c|c|c|c|}
\hline Variable & $\begin{array}{c}\text { PMSS } \\
\text { Mean (SD) }\end{array}$ & $t / F$ & $\mathrm{p}$-value \\
\hline \multicolumn{4}{|l|}{ Age } \\
\hline$\leq 24$ years & $23.79(7.35)$ & -1.13 & 0.26 \\
\hline$>24$ years & $24.51(8.35)$ & & \\
\hline \multicolumn{4}{|l|}{ Gender } \\
\hline Female & $23.46(7.44)$ & 1.89 & 0.06 \\
\hline Male & $24.66(8.15)$ & & \\
\hline \multicolumn{4}{|l|}{ Previous degree } \\
\hline Yes & $22.36(6.63)$ & -1.98 & 0.05 \\
\hline No & 24.37 (7.99) & & \\
\hline \multicolumn{4}{|l|}{ Source of funding } \\
\hline Self-funded & $23.57(8.55)$ & 0.22 & 0.80 \\
\hline Parents/Family & $24.16(7.76)$ & & \\
\hline Scholarship & $24.76(8.82)$ & & \\
\hline \multicolumn{4}{|l|}{ Adherence to faith } \\
\hline Strong & $22.31(7.47)$ & 39.44 & 0.001 \\
\hline Fair & $26.34(7.53)$ & & \\
\hline Poor & $30.60(6.73)$ & & \\
\hline \multicolumn{4}{|l|}{ Ease of funding course } \\
\hline Easy & $22.02(8.77)$ & -3.37 & 0.001 \\
\hline Difficult & $24.68(7.55)$ & & \\
\hline \multicolumn{4}{|c|}{ Motivation to study medicine? } \\
\hline Parents decision & $27.20(7.98)$ & 10.40 & 0.001 \\
\hline Role model & $24.84(7.88)$ & & \\
\hline Financial stability & $27.22(8.81)$ & & \\
\hline Desire to help others & $22.96(7.38)$ & & \\
\hline \multicolumn{4}{|l|}{ Alcohol use (AUDIT) } \\
\hline No problem & $23.63(7.63)$ & -5.53 & 0.001 \\
\hline Problem drinking & $29.74(8.37)$ & & \\
\hline \multicolumn{4}{|c|}{ Other psychoactive substance use (DAST-10) } \\
\hline Minimal risk & $23.99(7.76)$ & -1.90 & 0.06 \\
\hline Moderate-Severe risk & $26.38(9.18)$ & & \\
\hline \multicolumn{4}{|l|}{ Anxiety (HADS-A) } \\
\hline Absent & $23.20(7.65)$ & -4.87 & 0.001 \\
\hline Present & 26.54 (7.95) & & \\
\hline \multicolumn{4}{|l|}{ Depression (HADS-D) } \\
\hline Absent & $23.58(7.67)$ & -3.54 & 0.001 \\
\hline Present & $26.28(8.29)$ & & \\
\hline
\end{tabular}

Students whose level of adherence to their faith was good were less likely to report perceived medical school-related stress. Though the concept of spirituality and religiosity are divergent, some argue that there may be a link. In New 
Zealand, a study of the impact of religiosity on coping among medical students showed that religious affiliation correlated well with better coping skills. In this same study, students with greater religiosity were better able to handle stress based on the confession of faith, hope, and love. ${ }^{33}$ Furthermore, a survey of medical students in Trinidad and Tobago showed that those who regarded their faith as important and actively practiced it were less likely to report depressive symptoms and to report burnout. ${ }^{1}$

Table 6. Predictors of perceived medical school stress

\begin{tabular}{lcccc}
\hline Variable & B & $\begin{array}{r}\text { Standard } \\
\text { deviation }\end{array}$ & $t$ & p-value \\
\hline $\begin{array}{l}\text { Did not have a previous } \\
\text { higher degree }\end{array}$ & 1.705 & 0.959 & 1.78 & 0.076 \\
$\begin{array}{l}\text { Funding for medical } \\
\text { school not easy }\end{array}$ & 2.881 & 0.748 & 3.85 & 0.001 \\
Parent choice as & -3.105 & 0.621 & -5.00 & 0.001 \\
motivation for course & 2.376 & 0.308 & 7.725 & 0.001 \\
Poor adherence to faith & 5.196 & 1.077 & 4.82 & 0.001 \\
Problem drinking & 2.231 & 0.709 & 3.15 & 0.002 \\
Anxiety & 0.648 & 0.786 & 0.825 & 0.410 \\
\hline Depression & & & &
\end{tabular}

Although most students did not report alcohol use problems, those who reported problem drinking had significantly more medical school-related stress. The prevalence reported from this study is lower than the rate of $13.6 \%$ from Ilorin, North Central Nigeria. ${ }^{34}$ Under-reporting may be responsible for this lower rate. In a recent review of substance use patterns among medical students, psychoactive substance use was low among medical students compared to other university undergraduates. The commonest substance used was alcohol, followed by tobacco and cannabis, ${ }^{35}$ Problem drinking was also predictive of greater severity of stress. Alcohol abuse is a common maladaptive coping mechanism used by university students in Nigeria, ${ }^{34}$ and psychological distress has been shown to be associated with problem drinking among undergraduates in Africa. ${ }^{36-38}$ Alcohol consumption could also be a means to relieve symptoms of anxiety and/or depression, which was associated with higher levels of stress in this study. However, the cross-sectional design of this study limits the ascertainment of causality between alcohol abuse and psychiatric morbidity.

Over a quarter of the participants in this study report significant anxiety symptoms, and about a quarter had significant depressive symptoms. The prevalence of depression and anxiety symptoms are consistent with previous studies on psychiatric morbidity globally among medical students. ${ }^{39,40}$ It is not possible to determine causality or to ascertain the direction of the relationship between stress, psychoactive substance use, and psychiatric morbidity. However, the prevalence observed among a representative sample of medical students from Nigeria suggests that medical educators should be mindful of the effect of poor mental health on academic excellence in medical schools.
Poor mental health indices may be attributed to the high expectations from parents, relatives and teachers and the high level of competition among students in medical schools. Recently, the agency that regulates undergraduate medical education in Nigeria has set out to ensure that medical schools adhere to their allotted quota when training students. As a result, schools which admitted more than their allotted quota need to reduce the number of its students or risk losing its accreditation. This has led to greater competition for placement in senior classes among students. ${ }^{41}$ Students on scholarships could also have fears about losing scholarships if they are unable to maintain high grades consistently. The positive association between anxiety and depressive symptoms with perceived stress is consistent with findings of increased psychiatric morbidity linked to stress among medical students. ${ }^{42,43}$ Unfortunately, over the years the duration of training in mental health within the syllabus of medical schools in Nigeria is becoming increasingly shorter. Knowledge of psychological reactions to stress and recognition and management of resulting psychiatric morbidity would 'demystify' and reduce the stigma surrounding these conditions, enabling affected students to apply more adaptive coping skills and more readily seek help from appropriate sources when overwhelmed.

Our findings should be interpreted with the following limitations in mind. First, the cross-sectional design of this study did not enable us to ascertain the temporal association between perceived stress and its correlates. Second, an objective assessment of the academic performance of the study participants was not done, due to logistic constraints the authors viewed would arise from getting medical schools to release performance evaluation of participants. We also feared that participation rates in the study would be poor if students knew we would ask for their performance evaluation from their school. Third, other possible correlates like, occupation of parents, were not ascertained. In spite of this, the representativeness and large sample size in this study provides a valuable improvement on available evidence. We also suggest that future studies comparing stress across student disciplines and the general population be conducted to identify if perceived high-stress levels are related to the course of study.

\section{Recommendations}

The findings from this study are a call to educators in medical schools in Nigeria in particular and those in subSaharan Africa in general to improve mental health awareness in their curriculum, and foster mental health promotion programmes (such as education about risks of alcohol abuse, and adaptive ways to cope with stress) among undergraduate medical students. This would go a long way to mitigate the impact of psychiatric morbidity, reduce stigma associated with psychological problems and facilitate early help-seeking for students who develop mental health 
problems. Furthermore, to reduce the gap between available personnel and medical manpower needs in developing countries, governments should subsidise medical education, either through loans to students or bearing a large portion of education costs. Given the significant concerns of the medical students who participated in this study about their finances and its deleterious effect on mental health and stress. We also recommend that future research with a prospective design be undertaken to establish the temporal relationship between perceived stress and relevant sociodemographic and clinical correlates.

\section{Conflict of Interest}

The authors declare that they have no conflict of interest.

\section{References}

1. Youssef FF. Medical student stress, burnout and depression in Trinidad and Tobago. Acad Psychiatry. 2016; 40(1):69-75.

2. Sohail N. Stress and academic performance among medical students. J Coll Physicians Surg Pak. 2013; 23(1):67-71.

3. Gupta S, Choudhury S, Das M, Mondol A, Pradhan R. Factors causing stress among students of a Medical College in Kolkata, India. Educ Health (Abingdon). 2015;28(1):92-5.

4. Shah M, Hasan S, Malik S, Sreeramareddy CT. Perceived stress, sources and severity of stress among medical undergraduates in a Pakistani medical school. BMC Med Educ. 2010;10:2

5. Heinen I, Bullinger M, Kocalevent R-D. Perceived stress in first year medical students -associations with personal resources and emotional distress. BMC Med Educ 2017; 17:4

6. Iqbal S, Gupta S, Venkatarao E. Stress, anxiety and depression among medical undergraduate students and their socio-demographic correlates. Indian J Med Res. 2015;141(3):354-7.

7. Vitaliano PP, Maiuro RD, Mitchell E, Russo J. Perceived stress in medical school: resistors, persistors, adaptors and maladaptors. Soc Sci Med. 1989;28(12):1321-9.

8. Vitaliano PP, Maiuro RD, Russo J, Mitchell ES. Medical student distress. A longitudinal study. J Nerv Ment Dis. 1989;177(2):70-6.

9. Harding J. Financial circumstances, financial difficulties and academic achievement among first-year undergraduates. Journal of Further and Higher Education. 2011; 35(4):483-99.

10. Chowdhury R, Mukherjee A, Mitra K, Naskar S, Karmakar PR, Lahiri SK. Perceived psychological stress among undergraduate medical students: role of academic factors. Indian J Public Health. 2017;61(1):55-7.

11. Wolf L, Stidham AW, Ross R. Predictors of stress and coping strategies of US accelerated vs. generic Baccalaureate Nursing students: an embedded mixed methods study. Nurse Educ Today. 2015; 35(1): 201-5.

12. Vitaliano PP, Russo J, Carr JE, Heerwagen JH. Medical school pressures and their relationship to anxiety. J Nerv Ment Dis. 1984;172(12):730-6.

13. Kötter T, Voltmer E. Measurement of specific medical school stress: translation of the "Perceived Medical School Stress Instrument" to the German language. GMS Z Med Ausbild. 2013;30(2):22.

14. Sreeramareddy CT, Shankar PR, Binu VS, Mukhopadhyay C, Ray B, Menezes RG. Psychological morbidity, sources of stress and coping strategies among undergraduate medical students of Nepal. BMC Med Educ. 2007;7:26.

15. Bramness JG, Fixdal TC, Vaglum P. Effect of medical school stress on the mental health of medical students in early and late clinical curriculum. Acta Psychiatr Scand. 199; 84(4):340-5.

16. Chang E, Eddins-Folensbee F, Coverdale J. Survey of the prevalence of burnout, stress, depression, and the use of supports by medical students at one school. Acad Psychiatry. 2012; 36(3):177-82.

17. Omigbodun OO, Odukogbe A-TA, Omigbodun AO, Yusuf OB, Bella TT, Olayemi O. Stressors and psychological symptoms in students of medicine and allied health professions in Nigeria. Soc Psychiatry Psychiatr Epidemiol. 2006; 41(5):415-21.

18. Medical \& Dental Council of Nigeria. List of accredited medical schools in
Nigeria. 2016 [cited 22 April 2016]; Available from: https://www.mden.gov.ng/page/accredited-medical-schools.

19. Voltmer E, Kötter T, Spahn C. Perceived medical school stress and the development of behavior and experience patterns in German medical students. Med Teach. 2012; 34(10):840-7.

20. Saunders J, Aasland O. WHO collaborative project on the identification and treatment of persons with harmful alcohol consumption. Report on Phase I: Development of a screening instrument. Geneva; 1987 [cited 25 Oct 2017]; Available from: http://www.who.int/iris/handle/10665/62031.

21. Adewuya AO. Validation of the alcohol use disorders identification test (AUDIT) as a screening tool for alcohol-related problems among Nigerian university students. Alcohol Alcohol. 2005;40(6):575-7.

22. Chukwujekwu D, Okeafor C, Onifade P. Validity of Beck's depression inventory and alcohol use disorders identification test in Nigeria's Niger Delta region. Port Harcourt Med J. 2016;10(2):50.

23. Skinner HA. The drug abuse screening test. Addict Behav. 1982; 7(4):363-71.

24. Gavin DR, Ross HE, Skinner HA. Diagnostic validity of the drug abuse screening test in the assessment of DSM-III drug disorders. Br J Addict. 1989; 84(3):301-7.

25. Maly RC. Early recognition of chemical dependence. Prim Care. 1993; 20(1):33-50.

26. El-Bassel N, Schilling RF, Schinke S, Orlandi M, Sun W-H, Back S. Assessing the utility of the drug abuse screening test in the workplace. Res Soc Work Pract. 1997; 7(1):99-114.

27. Martino S, Grilo CM, Fehon DC. Development of the drug abuse screening test for adolescents (DAST-A). Addict Behav. 2000; 25(1):57-70.

28. Zigmond AS, Snaith RP. The hospital anxiety and depression scale. Acta Psychiatr Scand. 1983; 67(6):361-70.

29. Abiodun A. A validity study of the hospital anxiety and depression scale in general hospital units and a community sample in Nigeria. Br J Psychiatry. 1994;165:669-72.

30. Robichaud M, Dugas MJ, Conway M. Gender differences in worry and associated cognitive-behavioral variables. J Anxiety Disord. 2003;17(5):501-16.

31. Kettley N, Whitehead J, Raffan J. Worried women, complacent men? Gendered responses to differential student funding in higher education. Oxford Review of Education. 2008; 34: 111-129

32. Sreeramareddy CT, Shankar PR, Binu VS, Mukhopadhyay C, Ray B, Menezes RG. Psychological morbidity, sources of stress and coping strategies among undergraduate medical students of Nepal. BMC Med Educ. 2007;7:26.

33. Henning MA, Krägeloh C, Thompson A, Sisley R, Doherty I, Hawken SJ. Religious affiliation, quality of life and academic performance: New Zealand medical students. J Relig Health. 2015; 54(1):3-19.

34. Makanjuola AB, Daramola TO, Obembe AO. Psychoactive substance use among medical students in a Nigerian university. World Psychiatry. 2007; 6(2):112-4.

35. Roncero C, Egido A, Rodríguez-Cintas L, Pérez-Pazos J, Collazos F, Casas M. Substance use among medical students: a literature review 1988-2013. Actas Esp Psiquiatr. 2015;43(3):109-21.

36. Abayomi O, Onifade P, Adelufosi A, Akinhanmi A. Psychosocial correlates of hazardous alcohol use among undergraduates in southwestern Nigeria. Gen Hosp Psychiatry. 2013;35:320-4.

37. Adewuya A. Prevalence of major depressive disorder in Nigerian University students with alcohol-related problems. Gen Hosp Psychiatry. 2006;28:169-73.

38. Peltzer K, Malaka D, Phaswana-Mafuya N. Psychological correlates of substance use among South African University students. Social Behavior and Personality: An International Journal. 2001;29(8):799-806.

39. Wege N, Muth T, Li J, Angerer P. Mental health among currently enrolled medical students in Germany. Public Health. 2016; 132:92-100

40. Pan XF, Wen Y, Zhao Y, Hu JM, Li SQ, Zhang SK, et al. Preva-lence of depressive symptoms and its correlates among medical students in China: a national survey in 33 universities. Psychol Health Med. 2016; 21(7):882-9.

41. Oyewole N. Students' protests rock UNILAG, Yabatech. Daily Trust Newspapers. 2016 [cited 24 Feb 2016]; Available from: http://www.dailytrust.com.ng/news/general/students-protests-rock-unilagyabatech/133030.html.

42. Midtgaard M, Ekeberg Ø, Vaglum P, Tyssen R. Mental health treatment needs for medical students: a national longitudinal study. Eur Psychiatry. 2008;23:50511.

43. Tyssen R, Vaglum P, Grønvold N, Ekeberg Ø. Factors in medical school that predict postgraduate mental health problems in need of treatment. A nationwide and longitudinal study. Med Educ. 2001;25:110-20. 